FORBES \& FIFTH 


\section{Kathryn Sehlesinger}

Mas it all those years without $\sqrt{\text { winters that inspired Kathryn }}$ Schlesinger to investigate the year without a summer? The University of Pittsburgh junior, who is double majoring in Environmental Studies and History, grew up in subtropical Palm Beach Gardens, Florida, where she played catcher on the Palm Beach Gardens Lady Gator travel softball team for close to ten years, played piano since the age of six, and played with her cat, Mr. Frosty, as much as possible. Her lifelong cloudgazing and interest in climatology will take her to Yellowstone National Park this summer for fieldwork in geology, ecology, and environmental ethics. Kathryn plans to pursue a career in environmental policy, preferably in a city with four distinct seasons. 
FORBES \& FIFTH

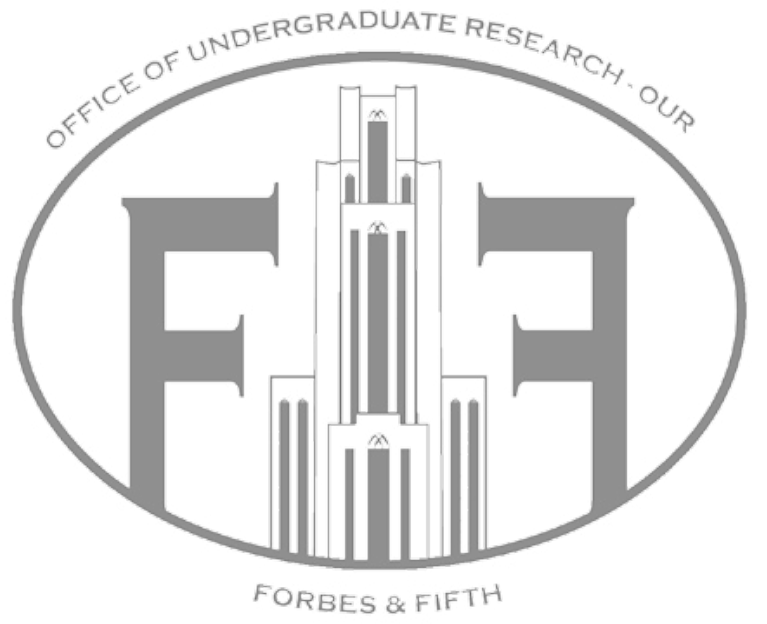




\section{The "Romantic" Year Without a Summer The Little Ice Age's Cultural Impact on Early Nineteenth Century Britain}

\section{Introduction}

In 1816, an English vicar wrote: "During the entire season the sun rose each morning as though in a cloud of smoke, red and rayless, shedding little light or warmth and setting at night behind a thick cloud of vapor, leaving hardly a trace of its having passed over the face of the earth." This kind of documentation was prevalent during the spring of this year. The entire world faced dramatic climate changes following the eruption of Mount Tambora the previous year. Consequently, ash lingered in the atmosphere over much of the world for up to two years, producing unusual weather. ${ }^{2}$ These were certainly unfamiliar times for Europe, North America, and specifically, for Britain.

What was the Little Ice Age and what impact did it have on Britain in the nineteenth century? The Little Ice Age spanned a period of about 500 years, though this figure is highly debated amongst historians and scientists due to fluctuations in the recording of scientific data. These fluctuations resulted from less evidence documented or found in records during the Middle Ages and the initial portion of the Little Ice Age. For the purpose of this paper, the Little Ice Age is established as the period of 1300-1850. During this period, the world was devastated by climate change observed through dramatic fluctuations in weather patterns and temperatures, droughts, flooding, and famine - all of which had a societal impact.

The majority of evidence and scholarly material on the impact of the Little Ice Age focuses on the period between the 15th and 18th century. Conversely, the years 1805 to 1820 were, for many Europeans, the coldest of the era. This paper will discern the degree of influence the extreme climatic fluctuations had on both the culture and societal structure of Britain during the 1810s by observing the resulting rise in artistic development, the incredible negative response and opinion of the common people, and finally, the overall "romantic" ideology embedded in early nineteenth century British culture. 


\section{The Effect on Landscape Art}

The general landscape of Britain during the 1810 decade reflected a time in which Britain was experiencing the height of its industrial revolution. Simultaneously, Britain was experiencing some of the coldest decades recorded, including one of the coldest years, referred to

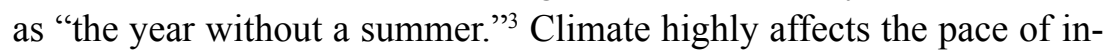
dustrialization and the overall productivity of a country. However, it can be argued that climate will most directly affect the culture and artistic perspective in a society.

The "Society for the Encouragement of Arts" had existed in London since 1754. Soon after its establishment, the Society began flourishing. ${ }^{4}$ This prosperous artistic community promoted a vast number of outlets through which artists could incorporate their transitioning views of society into their artwork. As in any society, there was clear dissonance between the actual works artists produced and the expectations society held for them. Generally, the people expected artists to produce pieces that were calming, pure, stable, and calculated. The middle class' interest in the fine arts increased, imbued by a spirit of positive encouragement towards the artists. ${ }^{5}$

In 1810 s transitioning period, the artist's primary concern was to advance his reputation and status, both as a painter and lecturer. Such advancement was generally best served by avoiding controversy. ${ }^{6}$

Additionally, this was a period of social unrest, pillaging, rioting, and criminal violence, all of which erupted across Europe, reaching climax in the year $1816 .^{7}$ These events were all partially attributed to the degrading climatic patterns in Britain which greatly amplified the sociopolitical struggles happening concurrently. While the people blindly reacted through the means of violent revolts against these events, the landscape painters took a subtler but equally strong approach to these changes.

As previously mentioned, the role of art in society and on its audience changes and depends on the status and structure of the present society. In the midst of industrialization, the majority of artists, including J.M.W Turner, John Constable, and John Linnell, were anti-industrialists, focusing their energies on creating their images and beliefs around naturalism. During the 1810 s and the 1820 s, naturalism was a popular sub-movement and ideology incorporated into the Romantic 


\section{Schlesinger}

Movement.

Before discussing the influence the climate had on the work of landscape painters (such as Turner), it is important to first note the overall goal of landscape painters when producing these naturalistic works. These visionary painters created a new tradition of producing works that expressed mist and cloudy skies. They discovered the beauty of an atmosphere which possessed a life of its own and bathed every object in fog. This type of art was described as supremely pure while also being permeated by a vague mysticism aimed to maintain the love of nature, more vigorously than in any other country in Europe. These little pictures, seen as simplistic and basic by some, are

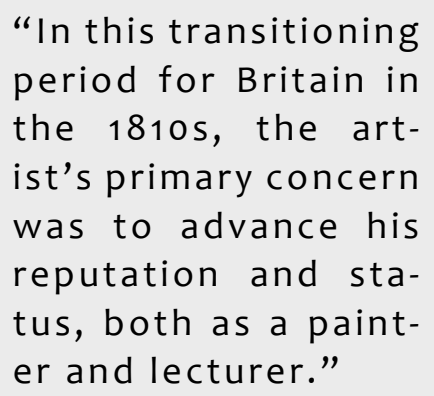

scenes depicting everyday life, often in a country setting. ${ }^{8}$

The discussion now returns to the impact of climate on British landscape art during the tumultuous 1810s. Artists' implementation of naturalism into their works resulted in de-emphasizing the industrial movement, which correlated with the pattern of climatic fluctuations that plagued this decade. Through naturalism, artists like Turner and Constable attempted to convey the "truth" within nature by frequently developing landscapes with storm scenes, ${ }^{9}$ as well as subtly portraying landscapes with the whole canvas covered by a patchwork of light and shade from a partly cloudy sky. ${ }^{10}$

Scientifically, this "truth" was a product of the volcanic eruption of Mount Tambora, in Indonesia, in 1815. The eruption caused ash to be released and linger in the atmosphere over much of the world, originating from the Dutch East Indies, for up to two years. Consequently, this produced extremely unusual weather patterns. ${ }^{11}$ The result of this reality was Britain experiencing the "year without a summer" in 1816, which would provide the naturalistic landscape painters, such as Turner, the opportunity to capture nature's "truth" and devastatingly beautiful environment. ${ }^{12}$

Cloud cover is one of the characteristics of the climate change 
partially caused by the eruption of Mount Tambora. The resulting cloudiness in landscape paintings created an overshadowing element of darkness on British society that already loomed heavily due to social upheaval and discontent. This darkness only perpetuated the coldness and despair of the people, as well as the artists' concept of nature as an ambivalent force working with the people rather than against them.

According to an extremely detailed study conducted by Hans Neuberger, cloud cover proved to have an unexpected impact on the path taken by a great deal of artists in

"These visionary painters... discovered the beauty of an atmosphere which possessed a life of its own and bathed every object in fog." response to the movement of naturalism during this time period. ${ }^{13}$ The results showed that over the course of the Little Ice Age, cloud cover in paintings slowly increased over time. It is now evident that low cloud cover began to sharply increase after 1550 and fell significantly after 1850 . These variations were recorded by artists working outside, generally in the summer, and are in line with what might be expected from the known variations of summer temperature. ${ }^{14}$ The average temperature of the summer during three months (June-August) in 1816 was 13.4 degrees Celsius, almost as low as the coldest years in the Little Ice Age period (13.2 degrees Celsius in 1695, 13.1 degrees Celsius in 1725). ${ }^{15}$

In Britain, eighteenth and early nineteenth-century summer artists regularly painted fifty to seventy-five percent cloud cover into their summer skies. ${ }^{16}$ A scientific study conducted in 2007 by a group of Greek atmospheric and meteorological scientists emphasized a new look at the reconstruction of the aerosol optical depth before, during, and after major volcanic eruptions by studying the coloration of the atmosphere in paintings portraying sunsets in the period 1500-1900, when atmospheric observations were scarce and largely non-existent. The results showed that out of 181 painters from this period of time, 54 of them - Turner being one - fell into the category of having "volcanic sunset paintings," which were all created within three years of a major volcanic eruption. ${ }^{17}$ 


\section{Schlesinger}

\section{The Effect on Literature}

In comparison to landscape painting literature is generally directly influenced and motivated by controversial events: themes of society that cause discontent and allude to unpopular structure of some part of a society. For Britain in the nineteenth century, developing themes of separate realism and rationalism, as well as romantic realism can be defined as utilizing the romance to describe the manners of a previous state of society, relating as truthfully as possible to the history of a period and country. ${ }^{18}$ However, realism became less common among many writers and poets during this decade, as many individuals involved were driven to explore new elements and concepts.

Due to the distinct atmosphere of the "year without a summer" - one marked by hailstorms, violent thunder showers, and cold and gloomy weather - prominent literary figures from this decade have been considered to have been profoundly impacted by this weather. For instance, Lord Byron took up residence at the Villa Diodati, where the average summer temperature in Geneva was the lowest since 1753. Byron and his houseguests, including Mary Wollstonecraft Shelley and Percy Bysshe Shelley, stayed indoors and began entertaining themselves and each other with stories. ${ }^{19}$ Allegedly, this inspired Mary Shelley to invent her classic work, Frankenstein. ${ }^{20}$

The apprehension of British societies was fueled largely by an increasingly difficult harvest, culminating in August, 1816. Harvest deficiencies leading to food scarcity in Britain ${ }^{21}$ caused a popular London newspaper, The Times, to announce, in a delayed message, the precariousness of the harvest outlook in late July: "Should the present wet weather continue, the corn will inevitably be laid and the effects of such a calamity and at such a time cannot be other than ruinous to the farmers, and even to the people at large." 22 As a result, an overall sentiment of pessimism and cynicism permeated the beliefs of the British people, as nature itself challenged the efforts of society.

Byron and Shelley's shared experiences in Geneva were encapsulated in their works through the incorporation of science fiction and horror themes. Both Shelley's novel Frankenstein ${ }^{23}$ and Byron's poem "Darkness" summarized the supernatural beliefs of the time - beliefs providing these works with dark and supernatural horror stories. Interestingly enough, these works were created during the height of Romanti- 
cism.

Explaining Romanticism and the elements of this ideology that translated to society during this period of time would prove a most difficult and controversial subject. Many scholars have debated that there are some signs that interest in the literary use of myth was reviving. Currently, closer attention is being paid to the interrelations of history and myth. ${ }^{24}$ This might explain the fascination of authors of this period with "the myth," the archetypical concept that Romantic works focused around the elements of science fiction and horror. Myths can be defined as "fictions and metaphors that identify aspects of human personality with the natural environment, such as stories about sun-gods or tree gods." ${ }^{25}$ This "myth" in Romantic literature stemmed from, as Northrop Frye stated above in A Study of English Romanticism, the intertwining of the natural environment and these "fictions and metaphors" creating a unique atmosphere for artists to construct their horrifying perspectives given a specific historical context. The historical context during this period of time for the British was a landscape of discontent and unrest stemming from the events leading up to and following the "year without a summer."

\section{The Effect on the Common People: Social Unrest Erupts}

"Abide with me; fast falls the eventide; the darkness deepens; Lord, with me abide." ${ }^{26}$ As this darkness deepened during the "year without a summer" and lingered afterwards, a wave of reactionary movement occurred, directly contrasting with Romanticism, realism, and rationalism, which were observed as the main pillars of society. Apocalyptic fervency took hold of society during this year, and writers responded in a similar fashion. Farmworkers with iron-studded sticks and flags bearing the words "Bread or Blood" 27 directly contrasted to this extremist approach. However, the people's direct reaction to an apocalypse was much stronger than that of the writers who only embodied this movement due to the historical context of the time.

Newspapers, such as the London Chronicler, responded to the climatic fluctuations and resulting social, economic, and political impact by stating: "the large spots which may now be seen upon the sun's disk have given rise to ridiculous apprehension and absurd predictions. These spots are said to be the cause of the remarkable and wet weather 
we have had this summer and the increase of these spots is represented to announce a general removal of heat, from the globe, the extinction of nature, and the end of the world." ${ }^{28}$ However, at this time, there was little understanding of the full implications of whether these spots indicated any real danger. Instead, these spots were used as another reason to perpetuate an exaggerated response to the sudden and dramatic climactic and environmental changes during this time. By fueling the media to create such definitive and abrasive commentary on the environment during and around 1816, people's reactions became exponentially more reactive and petrified of nature's wrath.

For centuries, the popular reaction to poor harvests and famine had been fervent prayer or civil disturbance..$^{29}$ Especially with any threat of an apocalyptic world, the British people prepared with a response considered both superstitious and an embrace of the reality for what many believed would be "The End." The subsistence crisis during 1816 and 1817 promoted the most apocalyptic and reactionary responses from the British. A religious commotion in the western world was kindled where religious enthusiasm had been another

"Abide with me; fast falls the eventide; the darkness deepens; Lord, with me abide." indicator of social pathology. Accordingly, the more severe the distress, the more intense the religious excitement would be. ${ }^{30}$

Consequently, the religious fervency correlated with the violence of 1816 and 1817. The rate of crime, the prosecution of theft, and the amount of vandalism and arson were all indicators of the violent responses by British and other Europeans to these difficult times. Many of these, including arson, were developed specifically into an endemic European phenomenon during the subsistence crisis. ${ }^{31}$ To counteract the three types of evils that society had taken up (moral, physical, and metaphysical), many individuals in Britain began the practice of Theodicy, which was a practice found in many Eastern traditions embedded in practices of mysticism. The incorporation of Theodicy in Britain during the 1810 s explained the struggle faced by the people to naturally attempt to rationalize how God could exist through such horrible times and still deliver such evil. Due to the nature of religious philosophies, this idea 
provided people with ongoing reflections of themselves, Britain, and humanity as a whole in an attempt to explain the trying circumstances. ${ }^{32}$

On one side of the spectrum, the vengeance and wrath of nature caused passive apocalyptic beliefs. Due to the impact of chaos, additional tensions amongst classes, and economic strains on society, these beliefs would result in violent apocalyptic visions of the world. As people reacted according to this formula, they would continue to fuel their misery by resorting to such extreme levels of religious devotion and superstition, continuing the endless cycle that trapped British society for another decade following 1816.

\section{Conclusion}

The decade of the 1810 s in Britain was characterized by tumult that violently impacted the country and the entire world. While there was an incredible amount of social unrest, economic disaster, and violent response, the climatic fluctuations of the Little Ice Age that produced some of the coldest years in modern history led to the creation of some of the most influential art and literature of the nineteenth century.

While the early nineteenth century experienced the height of Romanticism (as seen in themes of society), the historical context altered the way in which literature and art were regarded as "romantic" or "unromantic." The perception of beauty translated to a world full of submovements fueled by a darkness that perpetuated a time full of horrors, a question of faith, and a greater understanding of the consequences of natural events.

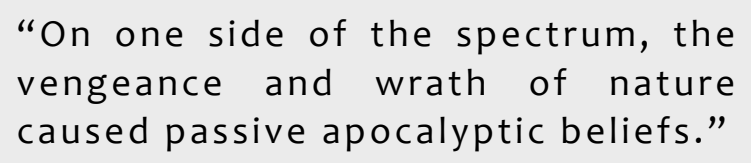


Schlesinger 